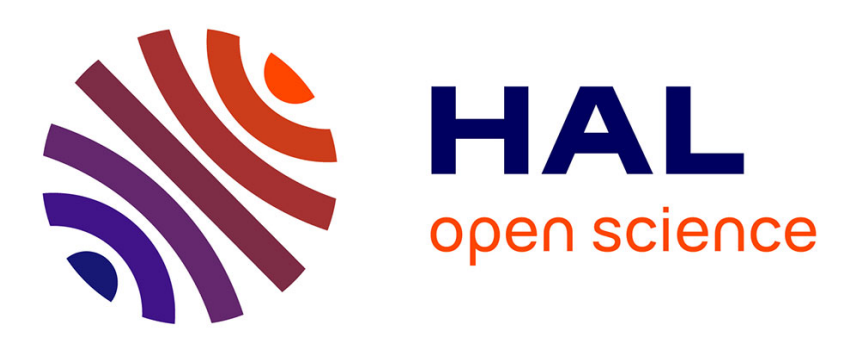

\title{
When the vibrations allow for anticipating the force to be produced: an extend to Pfister et al. (2014)
}

Guillaume Thébault, Arthur-Henri Michalland, Vincent Derozier, Stéphane

Chabrier, Denis Brouillet

\section{- To cite this version:}

Guillaume Thébault, Arthur-Henri Michalland, Vincent Derozier, Stéphane Chabrier, Denis Brouillet. When the vibrations allow for anticipating the force to be produced: an extend to Pfister et al. (2014). Experimental Brain Research, 2018, 236 (4), pp.1219-1223. 10.1007/s00221-018-5190-x . hal-02101611

\section{HAL Id: hal-02101611 \\ https://hal.science/hal-02101611}

Submitted on 16 Apr 2019

HAL is a multi-disciplinary open access archive for the deposit and dissemination of scientific research documents, whether they are published or not. The documents may come from teaching and research institutions in France or abroad, or from public or private research centers.
L'archive ouverte pluridisciplinaire HAL, est destinée au dépôt et à la diffusion de documents scientifiques de niveau recherche, publiés ou non, émanant des établissements d'enseignement et de recherche français ou étrangers, des laboratoires publics ou privés. 


\title{
When the vibrations allow for anticipating the force to be produced: an extend to Pfister et al. (2014)
}

\author{
Guillaume Thébault, $\mathrm{PhD}^{\mathrm{a}, \mathrm{b}}$, Arthur-Henri Michalland, $\mathrm{MSc}^{\mathrm{b}, \mathrm{c}}$, Vincent Dérozier, $\mathrm{PhD}^{\mathrm{d}}$, \\ Stéphane Chabrier, MD ${ }^{\mathrm{a}, \mathrm{e}}$, Denis Brouillet, $\mathrm{PhD}^{\mathrm{b}}$
}

a. INSERM, UMR1059 SAINBIOSE, Univ Jean-Monnet, Univ Lyon, F42023, Saint-Étienne, France

b. Univ Paul Valéry Montpellier 3, Univ Montpellier, EPSYLON EA 4556, F34000, Montpellier, France

c. LIRMM: Laboratory of Informatics, Robotics, Microelectronics of Montpellier, University of Montpellier CNRS, 860 rue de St Priest 34095 Montpellier cedex 5, France

d. Institut Mines Télécom - Mines Alès - Euromov Université de Montpellier

e.CHU Saint-Étienne, French Centre for Paediatric Stroke/Paediatric Physical and Rehabilitation Medicine

Department, INSERM CIC1408, F42055, Saint-Étienne, France

\section{E-mail adresses}

Guillaume Thébault, guillaume.thebault@univ-st-etienne.fr Arthur Michalland, arthur-henri.michalland@univ-montp3.fr Vincent Dérozier, vincent.derozier@mines-ales.fr Stéphane Chabrier, stephane.chabrier@univ-st-etienne.fr Denis Brouillet, denis.brouillet@univ-montp3.fr

Corresponding author

Guillaume Thébault

Université Paul Valéry Montpellier III, Laboratory Epsylon EA4556

34090 Montpellier, France.

$+33411757065$

guillaume.thebault@univ-st-etienne.fr

Word count: 2618 


\begin{abstract}
According to the Ideomotor Theory, action selection is done by the mental anticipation of its perceptual consequences. If the distal information processed mainly by vision and hearing are considered essential for the representation of the action, the proximal information processed by the sense of touch and proprioception is of less importance. Recent works seem to show the opposite. Nevertheless, it is necessary to complete these results by offering a situation, more ecological, where response and effect can occur on the same effector. So, the goal of our work was to implement a more relevant spatial correspondence because to touch is not the same action that to hear or to see.

To do so, participants pressed a specific key after the presentation of a stimulus. The key vibrated depending on the pressure exerted on it. In a compatible condition, high pressure on a key triggered a high vibration, while in an incompatible condition high pressure triggered a low vibration on the same effectors. As expected, the response times were faster in the compatible condition than the incompatible condition. This means that proximal information participates actively in the selection of action.
\end{abstract}

\title{
Keywords
}

Action, anticipation, tactile effects, body, ideomotor theory 


\section{Introduction}

Every action we perform causes specific effects in the environment. For instance, pressing a doorbell triggers a ring and consequences for inhabitant behaviour: opening the door. If you know that a baby sleeps in this home, you will delicately press the doorbell with your hand hoping that it will not wake up the baby. Schematically, a stimulus (the doorbell) is associated with a perceptual effect (bell ringing) and a response (to press). Similarly, ideomotor theory postulates that an idea, or an image, based on perceptual and body effects of actions, is enough to activate action representations (James 1890; Lotze 1852).

The modern conception of the ideomotor theory propose that actions are selected by their “auditory, visual, proprioceptive, kinesthetic and/or tactile" (Grenwald 1970, p.51) consequences. However, the theoretical issue of what effects are coded in action is still open (Shin et al. 2010).

Specifically, tactile or proprioceptive effects are presupposed to be more marginal than auditory and visual effects (Osiurak and Badets 2014; Pfister and Kunde 2013). For instance, in the Theory of Event Coding (TEC, Hommel et al. 2001) there is a distinction between the distal events related to objects of environment and proximal events than concern the physical perception like body sensations. By drawing on the need to constantly refer on our kinaesthetic and tactile perceptions, the Theory "assumes that action planning is based on distal representations" (Hommel, 2009, p. 516). This position is also the one of James (1890).

Derived from the Greenwald paradigm, Hommel and collaborators (Elsner and Hommel 2001, 2004; Hommel et al. 2001) proposed a two-phase procedure to explore distal effects. In the first phase, participants pressed right or left keys after the presentation of a white rectangle. Each response key triggered a tone; for instance, the right key triggered a high tone, while the left key triggered a low tone. In the test phase, the tone was presented and participants pressed the key as quickly as possible. In one condition, the relations between tone and response key were similar to the acquisition phase; in another condition, the tone and response key were different. Elsner and Hommel (2001) showed that participants were faster to press the key in the similar condition than the non-similar condition. Recently, it has been showed that proprioceptive perceptions were integrated in the same representation as action (Camus et al. 2016; Camus et al. 2017). So, the proximal effects could be less marginal than what is mentioned in TEC. 
These proximal effects were more specifically explored with the response-effect compatibility paradigm (Kunde 2001). Indeed, for Kunde (2001), the anticipation of action cannot be demonstrated if the effect precedes the participant's response as used in Elsner and Hommel's (2001) experiments. Thus, he proposed a procedure that does not require a test phase, and where effects always occur after responses. This procedure is simple and relatively similar to our example and other ecological learning situations. For instance, pressing a key triggers a tone. In one condition (compatible condition), the pressure exerted on the key is compatible with the intensity of the tone (i.e., high pressure triggers a high tone), while in the second condition (incompatible condition) the pressure exerted will be followed by an incompatible tone (i.e., low pressure triggers a high tone). Kunde (2001) found that response times were faster in the compatible condition than in the incompatible condition, showing the role of distal effects in the anticipation of action.

Recently, based on Kunde's paradigm, Pfister et al. (2014) and Wirth et al. (2016) specifically explored proximal effects (see also ten Hoopen et al. 1982). They used a response-effect compatibility paradigm where participants answer to a stimulus and responses were followed by a tactile effect. For instance, in the first experiment of Pfister et al. (2014), after a stimulus presentation, participants pressed a response key which vibrated according to a spatial condition (i.e., compatible condition, the key pressed vibrates) or according to an incompatible spatial condition (i.e., the opposite key vibrates). The results showing faster answers in the compatible than incompatible were only found in the fifth quintile, but indicated an anticipation of actions depending on body effects. Pfister et al. (2014) interpreted these small effects as being due to the methodology used. In fact, in ecological situations if actions performed by the right hand can trigger auditory or visual effects on the left, there are few activities where the right hand triggers a body effect in the left hand. For Wirth et al. (2016), the small effect found by Pfister et al. (2014) could also be task-relevant so they proposed a new task. After the presentation of a stimulus (Stimulus), the participants moved a slider with one hand (Response) connected to a brush stimulating the opposite forearm (Effect). In one condition, the movement of the hand was similar to the movement of the brush on the skin of the opposite forearm (compatible condition), while in another condition, these movements were incompatible. Results showed a main effect of compatibility with response times being faster in the compatible condition than incompatible condition. These two studies appear to provide evidence in favour of tactile effects in the anticipation of an action. 
Nevertheless, if for distal information spatial correspondence between movement of hand and effects is probably always integrated during action, for proximal information it seems necessary to compare conditions which are which similar in ecological situations. Thus, it is quite unlikely in daily life to touch an object with left hand and to perceive consecutively a tactile effect with right hand (case of the study of Pfister et al., 2014). What is possible with auditory or visual effects is not appropriate with tactile effects.

To extend previous works on anticipation of action by tactile effects, we believe that it is crucial to match response, spatial compatibility and effect in the context of touch because an artificial compatibility could affect response times. In other words, we believe that response and effect must concern the same effector, that is to say the finger doing the action. .

Building on Pfister et al.'s (2014) and Kunde's (2001) studies, we proposed an experiment without spatial compatibility between response and effect to be more similar to an ecological situation. Our introductory example is a typical situation where pressing a key needs tactile afferences of the same hand. Indeed, despite your best endeavours, if you feel your finger sinking into the doorbell, you will expect to hear the baby crying. In our study, we designed a procedure to measure in the same location the effects of compatibility of pressure and vibration effects. We expected faster answers when high pressure was associated with a high vibration effect or low pressure was associated with a low vibration effect (i.e., compatible condition) in comparison to answers where high pressure was associated with a low vibration effect or low pressure was associated with a high vibration (i.e., incompatible condition).

\section{Methods}

\subsection{Participants}

Thirty-two participants took part in the experiment. All were naïve about the experiment's purpose and gave their free consent after being informed about study. The number of participants was in accordance with results carried out by GPower software (Faul et al. 2007).

\subsection{Materials}


We created two specific response keys for our experiment (Fig1a). On one side of the key, we placed a Force Sensitive Resistor (FSR, FSR-402 from Interlink Electronics, Santa Barbara, CA, USA, cf. Fig1a on the right) with a round sensing area 0.5 " in diameter. On the other side, we put a vibration motor like those used in a Smartphone (cf. Fig1a on the left). These keys were controlled by an Arduino interface (Arduino Leonardo, Somerville, MA, USA) that creates keyboard responses from captors (Fig1b). We calculated two distinct forces of pressure needed to trigger a response. The force to trigger low pressure was up to $25 \mathrm{cN}$ while the force needed to trigger high pressure was up to $77 \mathrm{cN}$. The vibrations oscillated in two different frequencies determined by the Arduino programme resulting in high or low vibrations. The frequencies of high vibrations were twice as high as low vibrations. Concretely, the key response vibrated according to two different levels as a function of the force of pressure exerted on the FSR by participants.
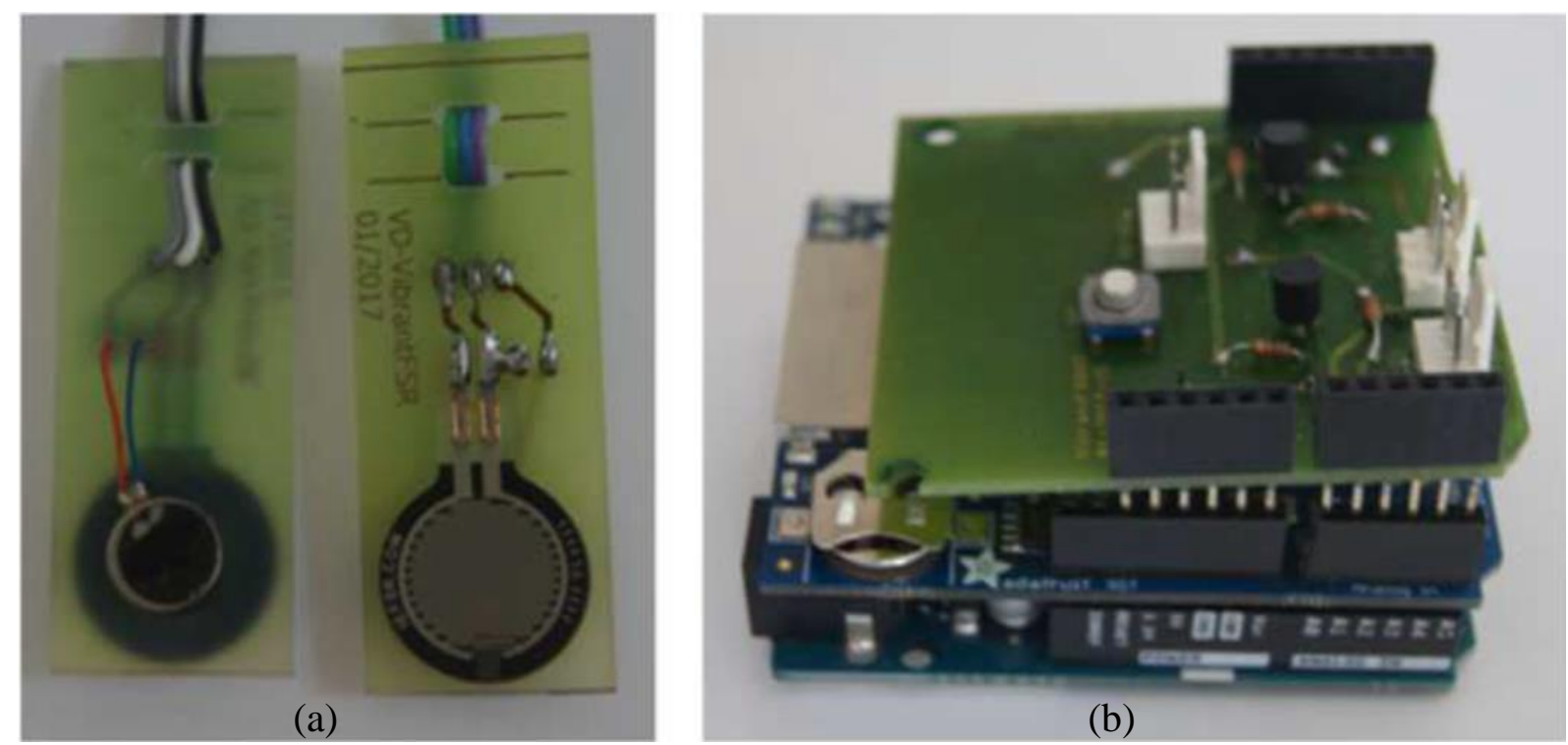

Fig 1 The keys were composed on one face by a motor and on other face by a force sensitive response (Fig1a, on the left). These keys were controlled by an Arduino interface (Fig1b, on the right)

\subsection{Stimuli and procedure}

The experiment was conducted in an isolated room. The participants seated in front of a computer with forearms on the table. Hands were placed at a similar distance from the middle of the screen. We instructed them to grasp a specific key (cf. Fig1a) between their thumb and their finger, as if they were grasping a key or a coin. 
The stimuli, two capital letters ( $\mathrm{H}$ and $\mathrm{X}$, Droid sans mono, 60pt), were presented for $250 \mathrm{~ms}$ in the centre of a 17" screen. The letters were in white on a black background. Participants were asked to press the response keys according to two levels of pressure depending on the stimuli (e.g., right key for $\mathrm{H}$ and left key for $\mathrm{X}$ ). The participants had to exert strong pressure on one key and low pressure on the other key as quickly as possible when the letters appeared. The vibrations (low vs high) were triggered after a $200 \mathrm{~ms}$ delay once the level of pressure had been reached. The duration of the vibration was $250 \mathrm{~ms}$. Participants had $1500 \mathrm{~ms}$ to respond after the presentation of stimuli. Then, the next trial started after an interval of $1000 \mathrm{~ms}$. Participants completed ten blocks of 16 trials in the compatible and incompatible conditions. The order of presentation of experimental conditions was counterbalanced. Half of the participants used their right hand to exert high pressure.

\section{Results}

Errors produced by participants $(6.25 \%)$ and responses under $150 \mathrm{~ms}$ and exceeding $1250 \mathrm{~ms}$ were removed from the statistical analysis. Then, for each participant, we applied a filter to exclude the responses at 2.5 SD above and below the mean in each condition of compatibility. We calculated quintiles of distributions for each participant and condition.

To examine the response times by quintiles in each condition, a 2 x 5 analysis of variance (ANOVA) was carried out to test the principal effects of compatibility and quintile, and then interaction effects. We found a significant effect of compatibility $\left(F(1,31)=4.74, p=.04, \eta^{2} \mathrm{p}\right.$ $=.13$ ); participants responded faster in the compatible condition than in the incompatible and a significant effect of quintile was found as expected $\left(F(31,124)=386, p<.001, \eta^{2}=.96\right)$. As shown in Fig2, a significant interaction effect was found $(F(4,24)=6.41, p<.0001)$. Analysis of this interaction showed only a significant effect for the higher quintile $(p=.01$, $\left.\eta_{\mathrm{p}}^{2}=.51\right)$. 


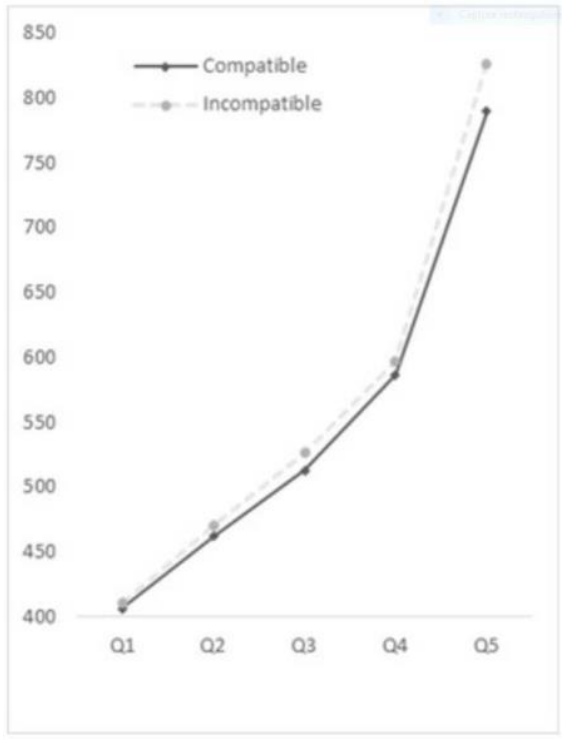

Fig 2 Results by quintiles of compatible and incompatible conditions

\section{Discussion}

The aim of this study was to provide evidence for the role of tactile effects in the anticipation of actions while the ideomotor theory implies that the proximal information processed by proprioception is of less importance for the representation of actions (Osiurak and Badets 2014; Pfister and Kunde 2013). If it is well established that distal effects (i.e., visual or auditory) are important for anticipation of action (e.g., Elsner and Hommel 2001; Kunde 2001; Kunde et al. 2004), few studies have shown a similar role for proximal effects (Pfister et al. 2014; Wirth et al. 2016).

Unlike Pfister et al. (2014), in our study, response and effect concerned the same effector (i.e. the finger doing the action). Our results highlighted that response times were faster when strongly (or weakly) pressing the response key was followed by a strong (or weak) tactile vibration than when response and effects were presented in an incompatible condition. Furthermore, we also observed an interaction effect of compatibility and quintile. More precisely like Kunde et al. (2001), Pfister et al. (2014) and Wirth et al. (2016), a significant effect of compatibility was found only in the last quintile of the distribution. So, as expected, tactile effects are well anticipated before response initiation.

If Pfister et al.'s (2014) results could be interpreted by the spatial coding brought about by tactile effects occurring during a task, our results were supported by tactile effects features. Thus, we strengthen the hypothesis that tactile effects play the same role as distal 
effects, highlighting the role of proximal effects in the ideomotor mechanism (James 1890; Badets et al. 2014; Pfister et al., 2014; Wirth et al., 2016).

Another explanation could take into account the origin of tactile stimulation. Indeed, we may wonder whether all the tactile vibrations really activate proximal effects whereas body sensations are either environment-related or related to the activity of the agent ${ }^{1}$. Thus, an assumption to be considered is that tactile effects following an action are distinguished by the subject as two distinct events by the source of sensation (Djikerman and De Haan 2007). Tactile proximal effects would be the sensations perceived by the subject when acting; tactile distal effects would be the sensations perceived by the subject when triggered by an event in the environment. This argument is legitimate insofar as our results are very similar to others (Kunde et al. 2001; Pfister et al. 2014; Wirth et al. 2016) highlighting the involvement of external stimuli (i.e., distal effects) and not those "internal to the body" (i.e., proximal effects). For instance, blind subject can perceive objects in the environment with sensory stimulations delivered via a specific device, but only if the subject is in an active exploration involving moto-sensory processes (Bach-y-Rita et al. 1969; Gapenne 2014; see also Varela et al. 1991). Interestingly, the perception of tactile sensors from a device is sometimes abolished by sensation arising from the environment, generating confusion between internal and external bodily events (Auvray et al. 2005; Gapenne 2014).

This argument leads us to think that proximal - distal might not be relevant. Indeed, a tactile stimulus is both distal (i.e., its origin via proprioceptive sensations) and proximal (i.e., the sensation it triggers).

So, we could consider the role of touch like another proximal effect grouping sensations and movements since movement is at the core of ideomotor mechanisms (James 1890). Previous research found a correspondence between force exerted with digits and perceptive effects allowing one to select and to initiate movement on the principle of bidirectional relations between motor and perceptual codes (Kunde 2001; Kunde et al. 2004). These relations reflect the integrative process during action (Blanchard et al. 2013; Camus et al. 2016, 2017). Taken together, anticipation of tactile and proprioceptive effects produced by movement, which encompasses motor control via the musculoskeletal framework (Kavounoudias et al. 2008; Stillman 2002), still need to be explored.

\footnotetext{
${ }^{1}$ Remote versus resident effects for Shin et al. (2010).
} 


\section{References}

Auvray M, Hanneton S, Lenay C, O'Regan JK (2005) There is something out there: distal attribution in sensory substitution, twenty years later. J Integr Neurosci; 4:505-521.

Bach-y-Rita P, Collins C, Saunders F, White B, Scadden L (1969) Vision substitution by tactile image projection. Nature 221:963-4.

Badets A, Koch I, Philipp AM (2014) A review of ideomotor approaches to perception, cognition, action, and language: Advancing a cultural recycling hypothesis. Psychol Res 80:1-15.

Blanchard C, Roll R, Roll JP, Kavounoudias A (2013) Differential contributions of vision, touch and muscle proprioception to the coding of hand movements. PloS one 8, e62475.

Camus T, Brouillet D, Brunel L (2016) Assessing the functional role of motor response during the integration process. J Exp Psychol Hum Percept Perform 42:1693-1702.

Camus T, Hommel B, Brunel L, Brouillet T (2017) From anticipation to integration: the role of integrated action-effects in building sensorimotor contingencies. Psychon Bull Rev. https://doi.org/10.3758/s13423-017-1308-6.

Dijkerman HC, De Haan EH (2007) Somatosensory processes subserving perception and action. Behav Brain Sci 30:189-201.

Elsner B, Hommel B (2001) Effect anticipation and action control. J Exp Psychol Hum Percept Perform 27: 229-240.

Elsner B, Hommel B (2004) Contiguity and contingency in action-effect learning. Psychol Res, 68:138-154.

Faul F, Erdfelder E, Lang AG, Buchner A (2007) G* Power 3: A flexible statistical power analysis program for the social, behavioral, and biomedical sciences. Behav Res Methods, 39:175-191.

Gapenne O (2014) The co-constitution of the self and the world: Action and proprioceptive coupling. Front Psychol, 5:594.

Greenwald AG (1970) Sensory feedback mechanisms in performance control: With special reference to the ideo-motor mechanism. Psychol Rev, 77:73-99.

Hommel B, Müsseler J, Aschersleben G, Prinz W (2001) The theory of event coding (TEC): A framework for perception and action planning. Behav Brain Sci 24:849-877.

Hommel B (2009) Action control according to TEC (theory of event coding). Psychol Res 73:512-526

James W (1890) The principles of psychology. Harvard University Press, Cambridge.

Kavounoudias A, Roll JP, Anton JL, Nazarian B, Roth M, Roll R (2008) Proprio-tactile integration for kinesthetic perception: An fMRI study. Neuropsychologia 46:567-575.

Kunde W (2001) Response-effect compatibility in manual choice reaction tasks. J Exp Psychol: Hum Percept Perform 27:387-394. 
Kunde W, Koch I, Hoffmann J (2004) Anticipated action effects affect the selection, initiation, and execution of actions. Q J Exp Psychol 57:87-106.

Lotze HR (1852) Medicinische Psychologie oder Physiologie der Seele [Medical psychology or the physiology of the mind]. Weidmann'sche Buchhandlung, Leipzig.

Osiurak F, Badets A (2014) Pliers, not fingers: Tool-action effect in a motor intention paradigm. Cognition 130:66-73.

Pfister R, Janczyk M, Gressmann M, Fournier LR, Kunde W (2014) Good vibrations? Vibrotactile self-stimulation reveals anticipation of body-related action effects in motor control. Exp Brain Res 232:847-854.

Pfister R, Kunde W (2013) Dissecting the response in response-effect compatibility. Exp Brain Res 224:647-655.

Shin YK, Proctor RW, Capaldi EJ (2010) A review of contemporary ideomotor theory. Psychol Bull 136:943-974

Stillman BC (2002) Making sense of proprioception: The meaning of proprioception, kinaesthesia and related terms. Physiotherapy 8:667-676.

Stock A, Stock C (2004) A short history of ideo-motor action. Psychol Res 68:176-188

Ten Hoopen G, Akerboom S, Raaymakers E (1982) Vibrotactual choice reaction time, tactile receptor systems and ideomotor compatibility. Acta Psychol 50:143-157.

Varela FJ, Thompson E, Rosch E (1991) The embodied mind: Cognitive science and human experience. MIT Press, Cambridge.

Wirth R, Pfister R, Brandes J, Kunde W (2016) Stroking me softly: Body-related effects in effect-based action control. Atten Percept Psychophys 78:1755-1770.

\section{Funding}

This research did not receive any specific grant from funding agencies in the public, commercial, or not-for-profit sectors. 